\title{
EDUCAÇÃO POLÍTICA NO BRASIL E NA ITÁLIA: DUAS HISTÓRIAS, MUITOS PROBLEMAS COMUNS
}

DOI: http://dx.doi.org/10.1590/2236-3459/69712

\author{
Marcus Aurelio Taborda de Oliveira ${ }^{1}$ \\ Universidade Federal de Minas Gerais, Brasil. \\ Conselho Nacional de Desenvolvimento Científico e Tecnológico, Brasil. \\ Paolo Bianchini² \\ Università degli Studi di Torino, Itália. \\ Dipartimento di Filosofia e Scienze dell'Educazione, Itália.
}

$\cos 80$

\begin{abstract}
Resumo
Apresentamos um conjunto de argumentos que visam evidenciar como a educação política é um projeto de difícil realização em países com características bastante similares, como são a Itália e o Brasil. Para tanto percorremos traços da sua definição em parâmetros legais, visitando a legislação, programas de ensino e a imprensa. Observamos que as preocupações de corte político nos processos educativos escolares dos dois países foram impulsionadas a partir de um mesmo período histórico, a saber, entre os anos 30 e 40 do século XX, com forte acento conservador. Seja na forma de disciplinas escolares ou de práticas educativas, nomeadas de diferentes maneiras ao longo do tempo, a educação política assumiu quase sempre uma dimensão ideológica de perpetuação do status quo. Em um momento de forte refluxo conservador como o atual, é difícil prognosticar o sucesso de qualquer iniciativa de educação política, na medida em que as práticas sociais, culturais e políticas mais amplas constantemente depõem contra valores que poderiam ser
\end{abstract}

1 Professor do Departamento de Ciências Aplicadas da Educação, da Faculdade de Educação, da Universidade Federal de Minas Gerais, onde se dedica ao ensino da História da Educação. Bolsista do CNPq. Coordenador do Núcleo de Estudos sobre os Sentidos e as Sensibilidades - NUPES, ligado ao GEPHE, na UFMG, onde desenvolve pesquisas sobre a história do currículo, a história da educação social e a história da educação dos sentidos e das sensibilidades. O presente trabalho é resultado da parceria estabelecida durante a realização do meu estágio pós-doutoral junto a Università degli Studi di Torino, em 2016, sob a supervisão do professor Paolo Bianchini, com apoio financeiro do CNPq na modalidade de bolsa de pós doutorado no exterior.

2 É doutor, pesquisador e professor associado de História da Educação junto ao Departamento de Filosofia e Ciência da Educação da Università degli Studi di Torino. Ocupa-se da História da Educação e das práticas de difusão da cultura na Europa entre os séculos XVIII e XXI. Tem se dedicado ao estudo das práticas e da teoria educativa da Companhia de Jesus entre os séculos XVIII e XIX, dos manuais escolares e à análise do sistema escolar e formativo do Reino de Savóia na idade moderna. É o coordenador nacional do Banco de Dados Italiano sobre Manuais Escolares (EDISCO). Faz parte do comitê científico do Museu da Escola de Torino (MUSLI). Desenvolve a função de juiz honorário junto à Corte de Recursos do Tribunal de Menores de Torino. 
considerados universais, atendendo aos interesses de todos, fim último da democracia.

Palavras-chave: educação política, educação cívica, história do currículo, Itália-Brasil.

\title{
POLITICAL EDUCATION IN BRAZIL AND ITALY: TWO STORIES, MANY COMMON PROBLEMS
}

\begin{abstract}
We present some arguments to show how political education is a difficult project to be implemented in countries with very similar characteristics, as Italy and Brazil are. Therefore, we seek traces of its definition within laws, legislation, school curricula and in the press. We note that the concerns of political type in the educational processes of the two countries have developed in the same historical period, that is between the $30 \mathrm{~s}$ and $40 \mathrm{~s}$ of the twentieth century, with a strong conservative accent. Whether in form of school subjects or as educational practices, differently defined over time, the political education has often taken the ideological dimension of perpetuation of the status quo. Today, at a time of strong conservative reflux, it is difficult to predict the success of any initiative relating to political education, in so far as the most prevalent social, cultural and political practices today are constantly opposite to the values that might be considered universal and serving the interests of all, the ultimate goal of democracy.

Keywords: political education, civics, history of curriculum, Italy-Brazil.
\end{abstract}

\section{EDUCACIÓN POLITICA EN BRASIL E ITALIA: DOS HISTORIAS, MUCHOS PROBLEMAS COMUNES}

\section{Resumen}

Presentamos un conjunto de argumentos destinados a mostrar cómo la educación política es un proyecto de difícil logro en países con características muy similares, al igual que Italia y Brasil. Por lo tanto, buscamos huellas de su definición en los parámetros legales, visitando la legislación, los programas educativos y la prensa. Observamos que las preocupaciones de cariz político en los procesos educativos escolares de los dos países fueron desarrollados en el mismo período histórico, es decir, entre los años 30 y 40 del pasado siglo, con un fuerte acento conservador. Ya sea en forma de materias escolares o prácticas educativas, llamados de diferentes maneras a través del tiempo, la formación política casi siempre ha asumido una dimensión ideológica de perpetuación del status quo. En un momento de fuerte reflujo conservador como el actual, es difícil predecir el éxito de cualquier iniciativa de educación política, en la medida en que las prácticas sociales, culturales y políticas más amplias son testigos siempre en contra de los valores que podrían ser considerados universales, a servicio de los intereses de todos, el objetivo final de la democracia.

Palabras clave: educación política, educación cívica, historia del curriculum, Itália-Brasil.

\section{L'ÉDUCATION POLITIQUE AU BRÉSIL ET ITALIE: DEUX HISTOIRES, BEAUCOUP DE PROBLÈMES EN COMMUN}

\section{Résumé}

Nous présentons une série d'arguments pour montrer comment l'éducation politique est un projet difficile à mettre en œuvre dans des pays ayant des caractéristiques très similaires, comme l'Italie et le Brésil. Par conséquent, nous cherchons des traces de sa définition dans les paramètres juridiques, dans la législation, dans les programmes scolaires et dans la presse. Nous notons que les préoccupations politiques dans les processus éducatifs et scolaires des deux pays se sont développées dans la même période historique, c'est à dire entre les années 30 et 40 du XXe siècle, avec un fort accent conservateur. Que ce soit sous la forme de matières scolaires ou des pratiques pédagogiques, définies différemment au fil du temps, l'éducation politique a souvent pris la dimension idéologique de la perpétuation du status quo. Dans une époque de forte reflux conservateur comme l'actuelle, il est difficile de prédire le succès de toute initiative politique relative à l'éducation politique, dans la mesure où les pratiques sociales, culturelles et politiques les plus répandues sont aujourd'hui constamment contraires aux valeurs qui pourraient être considérés comme universels et au service des intérêts communs, but ultime de la démocratie.

Mots-clés: éducation politique; éducation civique; histoire du curriculum; Italie-Brésil. 


\section{Introdução}

E

m tempo de formação por competências e contínua avaliação de todos os aspectos do sistema escolar, parece um pouco retrógrado questionar se ainda permanece na escola espaço para um projeto cultural de ampla envergadura. Neste contexto, arrisca-se passar por reacionário caso nos interroguemos sobre o espaço que a escola tem reservado para a política. Na verdade, as perguntas não parecem estar fora de lugar se inseridas na conjuntura certa: basta abrir os jornais de muitos países para perceber que, enquanto os professores e funcionários da escola estão fazendo o máximo para continuar a dar sentido à educação, transmitindo às gerações mais jovens o que herdamos daqueles que nos precederam, e o que aprendemos com a nossa própria vivência, os governos continuam a olhar com atenção para a escola não somente do ponto de vista econômico, mas, sobretudo do ponto de vista político-ideológico.

De fato, como bem sabemos, as questões políticas mais complexas são tratadas e resolvidas com base na leitura política e ideológica de uma dada situação. Alguns exemplos, aparentemente paradoxais, podem nos ajudar a apresentar de maneira mais explícita o problema do qual nos ocupamos: a União Europeia investe a cada ano milhões de Euros em pesquisa e na construção de projetos de formação do cidadão europeu na escola, mas não somente ali. Ao mesmo tempo em todo o Velho Continente se elevam vozes sempre mais fortes (o que é preocupante do nosso ponto de vista) que julgam com estranheza o projeto comunitário, e questionam a saída ou a permanência da União, como é o caso recente do Reino Unido. Países até poucos anos atrás firmemente democráticos e laicos, como a Turquia, assistem hoje a demissão de centenas de professores (da escola básica e superior) em resposta a um golpe fracassado - do qual eles não participaram ativamente - em função do seu suposto envolvimento ideológico no trabalho de propaganda contrário ao governo instituído. Ainda, outros países, como o Brasil, pensam a reforma do currículo e sobretudo da formação docente, que afetariam gravemente os direitos e as prerrogativas dos professores, em nome do interesse de se construir "uma escola sem partido", ao mesmo tempo em que se impõe um currículo por decreto do chefe do Estado, sem a discussão devida com a sociedade civil.

Em face desses e de outros exemplos, nos parece legítimo perguntar, de um lado, se é possível hoje uma educação política; e, do outro, qual espaço resta à educação cívica, inserida legitimamente na escola há pouco mais de meio século, e aparentemente destinada a desaparecer depois de uma não gloriosa e certamente muito breve história. São perguntas que todas as democracias deviam fazer. Como historiadores, sabemos bem que sempre foi muito difícil transmitir uma ideia de cidadão que não estivesse reduzida àquela do súdito ou do mero executor da vontade de um patrão ou de um governo despótico. Sabemos também que os regimes mais "fechados" têm muito mais facilidade em construir um ideal de formação do cidadão porque o modelo e os princípios que desejam transmitir são simples. Bem mais árdua é a tarefa das democracias, que devem explicar e acima de tudo pôr em prática valores mais elevados, porém difíceis de assimilar, tais como, a igualdade, a fraternidade, os direitos, os deveres, paz e solidariedade.

Assim, pretendemos, recorrendo à perspectiva histórica e colocando em diálogo duas realidades nacionais distintas, mostrar como a formalização de projetos de educação política nas escolas não raro esteve travestida de tentativas de doutrinação ideológica. Isso não invalida a nossa defesa que falta no âmbito da educação pública no Brasil e na Itália 
iniciativas de educação política que vão além das rubricas tais como OSPB - Organização Social e Política Brasileira, EMC - Educação Moral e Cívica ou Cittadinanza e Costituizione, de sucesso prático escasso.

Para tentar enfrentar essas inquietações nos valemos de um breve percurso sobre algumas fases da história da formação do "cidadão", para fazer um diagnóstico desta época regida pelo neoliberalismo e pela globalização econômica, na qual as democracias e as suas ideias de cidadão tem entrado em uma profunda crise. Portanto, motivados pelos debates recentes no Brasil e na Itália, percorremos uma documentação que inclui a legislação, documentos curriculares e a imprensa, na tentativa de compreender as diferentes formas de afirmação ou de apagamento da política nas escolas públicas dos dois países.

\section{Pistas para uma história da educação política no Brasil}

Talvez como um dos resultados da grande polarização política vista, recentemente, no Brasil, temos observado um conjunto de iniciativas legislativas que tentam evitar que a educação escolar assuma um caráter denunciado por alguns como "ideológico". O exemplo mais contundente, até aqui, talvez venha de Alagoas, que chegou a aprovar aquilo que foi denominado de "Escola Livre". Mais do que julgar o mérito da matéria, que tem sido denunciada como anticonstitucional por muitos pesquisadores e grupos de professores, e até mesmo por juristas e pela Procuradoria Geral da República, ela apresenta no seu cerne uma contradição para a qual tanto os seus defensores, quanto o legislador pouco atentaram: a escola republicana é, por princípio, laica, no sentido mais amplo do termo. Assim, qualquer tipo de proselitismo que atente contra a dimensão pública, republicana, democrática de educação já está, por princípio, sob suspeição, e isso está garantido na Constituição Brasileira de 1988.

Mas outros problemas advêm da tentativa desses grupos de influenciar em um domínio tão delicado como da educação pública. Primeiro, seus argumentos são carregados de senso comum e desconsideram a riqueza e a pluralidade que é a vida nas escolas brasileiras. Segundo, tomam os professores como estúpidos incapazes de pensar sobre a vida, a sociedade, a política e, mais grave, sobre seu próprio labor. Terceiro, desconsideram que a educação no seu sentido forte, o qual inclui a dimensão instrutiva, mas a ela não se reduz, se funda justamente em visões de mundo, e essas são, felizmente, plurais. Não se forma o pensamento sem dúvida, sem estranhamento, sem debate, sem divergência, sem conflito, sem diálogo. Logo, formar exige justamente a exposição, discussão e equação das diferenças. Daí que o ato de educar é político no sentido mais pleno do termo, simplesmente porque a vida não é uma equação que tem um denominador comum universal.

Partindo desse último aspecto, não pretendemos reiterar argumentos fortes contra o abuso e a arbitrariedade desse tipo de iniciativa, agora legalizada em Alagoas, mas já tramitando em outros estados brasileiros. Não cremos que elas terão vida longa porque a escola e os professores filtram aquelas influências estranhas à natureza do seu trabalho, mesmo que travestidas de legalidade. Se entendermos a política no sentido amplo como cuidado com a polis, e pensarmos que ela pode ser ampliada para uma ideia de cuidado com o mundo, então muito ainda precisa ser feito para que possamos chamar de educação política o que vimos na história dos dois países nos últimos 100 anos, aproximadamente. 
Mormente o que se viu foram iniciativas de doutrinação em defesa de um tipo especifico de projeto de sociedade ou Estado - o fascista italiano, aquele do Estado Novo ou da Ditadura Militar brasileiros. Isso, por princípio, é a redução da política, em alguns casos a sua eliminação, justamente porque tenta nivelar visões de mundo, suspendendo a diferença e aniquilando o contraditório. Nada mais antipolítico, portanto!

Mais do que uma rubrica - que pode vir nominada de Civilidade, Urbanidade, Educação Cívica, Educação Moral e Cívica, Organização Social e Política Brasileira entre outras possibilidades - a escola como instituição social de transmissão e preservação da cultura já cumpre um papel político inconteste. Não nos referimos àquela mal caracterizada ideia de uma "escola burguesa", pois entendemos que esse epíteto apenas embaralha e ofusca a dinâmica da história. Mas aquela escola destinada à formação geral das novas gerações se assentou em bases caracteristicamente políticas. Formar o cidadão, educar o homem novo, desenvolver o ethos do trabalho, educar para a paz, estimular o sentido republicano são todos esses aspectos grandes finalidades escolares que atravessaram, de maneira diversa conforme o tempo e o lugar, o próprio sentido da escola pública. Não por acaso autores da estatura de Condorcet e Marx desconfiavam, ou mesmo denunciavam, a escola estatal como mecanismo que esvaziaria o sentido da política ao produzir o que o primeiro denunciava como uma "religião cívica". Na sua pena a escola pública, ao formar as novas gerações, deveria produzir as condições para que o exercício da política, possível apenas para os homens livres, fosse pleno. Constrangida pelos interesses do Estado a escola pública obstaria aquele exercício ao educar em visões parciais, mutiladas, do mundo, o que contraria o fim último do exercício político.

A afirmação da escola nacional e de massas parece ter caminhado exatamente no sentido oposto, na medida em que já no seu nascedouro ela transmitiria, de maneira explicita ou sub-reptícia, um conjunto de valores que ajudariam a erigir e consolidar - em tese! - determinados projetos políticos de acordo com agendas bastante específicas, como bem mostra Circe Bittencourt (1990). Um caso que talvez possa unir as experiências italiana e brasileira é justamente a definição da língua. Se a unificação italiana de 1861 exigia a definição de um padrão linguístico comum a todo o país, o qual reduziria outras possibilidades de comunicação ao nível do costume ou do folclore, no Brasil as diferentes iniciativas de nacionalização impediram que imigrantes falassem livremente as suas línguas de origem - entre outros tantos aspectos -, justamente com a pretensão de uma sujeição do "elemento estrangeiro" à cultura pretensamente nacional, processo que teve o seu ápice com a Campanha de Nacionalização de 1938. Lembremos que entre tantas outras inciativas, no âmbito daquela Campanha o Estado Novo brasileiro legislou sobre a Educação Moral, Cívica e Física, as quais assumiriam o formato disciplinar nos currículos brasileiros e seriam "obrigatórias para a infância e a juventude de todo país" (BRASIL, Decreto-Lei 2.072 de 08/03/1940).

A análise do referido artefato legislativo deixa claro o viés particularista do mesmo:

Art. 2ํ - A educação cívica visará a formação da consciência patriótica. Deverá ser criado, no espirito das crianças e dos jovens, o sentimento de que a cada cidadão cabe uma parcela de responsabilidade pela segurança e pelo engrandecimento da pátria, e de que é dever de cada um consagrar-se ao seu serviço com maior esforço e dedicação. 
Parágrafo único. É também papel da educação cívica formar nas crianças e nos jovens do sexo masculino 0 amor ao dever militar, a consciência das responsabilidades do soldado e o conhecimento elementar dos assuntos militares, e bem assim dar às mulheres o aprendizado das matérias que, como a enfermagem, as habilitem a cooperar, quando necessário, na defesa nacional.

Art. 3ำ - A educação moral visará a elevação espiritual da personalidade, para o que buscará incutir nas crianças e nos jovens a confiança no próprio esforço, o hábito da disciplina, o gosto da iniciativa, a perseverança no trabalho, e a mais alta dignidade em todas as ações e circunstâncias.

Parágrafo único. A educação moral procurará ainda formar nas crianças e nos jovens de um e outro sexo os sentimentos e os conhecimentos que os tornem capazes da missão de pais e de mães de família. Às mulheres dará de modo especial a consciência dos deveres que as vinculam ao lar, assim como o gosto dos serviços domésticos, principalmente dos que se referem à criação e à educação dos filhos.

No que tange àquele entendimento amplo, antes referido, é claro que o texto legal reduz a perspectiva de educação política, na medida em que advoga papéis muito definidos para as jovens gerações brasileiras, sejam eles ligados à caserna ou à vida doméstica, com forte cunho utilitário. Mas merece destaque o art. $3^{\circ}$. do referido decreto, na medida em que ele elenca um conjunto bastante claro de pressupostos econômicos, capitalistas e/ou liberais, mas também marca de um socialismo de corte economicista: esforço, disciplina, iniciativa, a perseverança no trabalho. Naquele momento de grande expansão da industrialização no país, esses pressupostos estavam profundamente ancorados nos termos propostos no artigo precedente: a todos e a cada um cabe a responsabilidade pelo "engrandecimento" do país, algo que é considerado um serviço à pátria.

Lenharo (1986) e Horta (2012) já mostraram as bases sobre as quais foram fundadas tais representações da educação política naquele período. Mas não devemos esquecer que aqueles pressupostos esgarçados em um momento de grande boom industrial, de conflito mundial, e de práticas políticas autoritárias, tinham já um histórico que nos faz retroceder ao século XIX, pelo menos ao Instituto Histórico e Geográfico Brasileiro (IHGB) e ao pensamento historiográfico brasileiro, como bem delineiam Diehl (1988) e Odalia (1997).

Assim a política a ser ensinada e aprendida pela via das festas cívicas (desfiles, manifestações, orfeões, movimentos tais como a Juventude Brasileira), além de algumas disciplinas escolares, se prestavam, de fato, a formar um tipo especifico de mentalidade política, no qual o indivíduo era submetido ao imperativo da pátria, da família (e do mundo industrial). A educação política se assentava no desenvolvimento de um ethos do trabalho e de um individualismo relutante diante dos desígnios do poder do Estado, o qual na arena da grande política se contrapunha ao ideário liberal, mas não se imiscuía de fomentar alguns daqueles pressupostos em nome da sua própria manutenção. Isso mesmo que o preço a pagar fosse o silenciamento do divergente e o aniquilamento do indivíduo, ou mesmo da organização comunitária, tal como a lei de nacionalização deixou em evidência. Para o Estado demiurgo educação política era adaptação, sujeição, reiteração da tradição na nova ambiência do capitalismo industrial em desenvolvimento. A ênfase na família e a ideia de "incutir", expressa no mesmo art. 3ํ.., não deixam dúvidas em relação aos propósitos daquela legislação. Política, ali, definitivamente não é o exercício das diferenças para a construção de uma vida comum, e essa parece ter sido a tônica no período. 
Posteriormente, até pelo menos o começo do período ditatorial iniciado em 1964, e talvez obliterado pelos debates em torno do desenvolvimento econômico e do sentido público da escola brasileira, os quais culminariam na LDB 4.024/1961, o tema da educação política não ocupou grande destaque na agenda nacional. Pelo menos não diretamente, ou no âmbito do Estado, uma vez que movimentos como o Centro Popular de Cultura, da União Nacional dos Estudantes, nas suas diferentes facções, as Ligas Camponesas, e as ações de Paulo Freire em Pernambuco atestavam que a educação é, em si, uma dimensão da política.

Mas no interior do estado e das suas políticas, não por acaso é no começo da ditadura civil-militar que se inicia um amplo debate sobre o sentido da educação política, expressa em termos de educação cívica. Ainda no mesmo mês que viu a perpetração do Golpe de Estado, o Conselho Federal de Educação se pronunciava sobre as reivindicações de "entidades cívicas femininas", no Parecer 117/64, de 30 de abril. Definindo a educação moral e cívica como o que "há de mais essencial e básico na educação integral do homem" (BRASIL, 1964, p. 15), afirmava que "O momento atual, do Brasil e do mundo, está a exigir, efetivamente, maior atenção para a formação da consciência dos adolescentes, quanto aos seus deveres morais e cívicos". Lembrando que a Lei de Diretrizes e Bases já definia essa preocupação no seu art. 1‥, em relação ao ensino de grau médio, o parecer defendia a ação daquele Conselho na criação da disciplina Organização Social e Política Brasileira OSPB, "com o objetivo de criar no adolescente o amor pelas instituições integrantes da ordem social e política do seu país" (BRASIL, 1964, p. 16).

Como se vê, o problema é complexo e só poderá ser resolvido dentro de todo o conjunto dos fatores educativos, quer na escola, quer fora dela. Trata-se, no fundo, da formação de hábitos de natureza ética, causada não apenas pela aquisição de conhecimentos através de aulas, mas principalmente pelo calor afetivo das relações de pessoa a pessoa e pelo atrativo dos ideais vividos em comunidade. Consequentemente, para esse fim importa muito mais o ambiente humano com que se educa o adolescente, do que as matérias e as técnicas empregadas. Assim, a desejada educação moral e cívica dos educandos dependerá principalmente do ambiente e m que viverem e se desenvolverem, tanto na escola, como na família e na comunidade local. (BRASIL, 1964, p. 16)

Novamente a educação para a consciência dos deveres cívicos e morais e o amor pelas instituições aparece como horizonte da educação política. No entanto o parecerista, Cândido Padin, parece hesitar em afirmar a proeminência da escola naquele propósito. A escola, talvez como uma extensão da família, deveria com ela se entender para definir o fulcro daquilo que seria a educação cívica ou política: "Cabe aos pais, no desejado entrosamento com a escola, acompanhar o transcurso das atividades dos seus filhos, dentro e fora do regime escolar, acertando com os educadores uma atuação complementar e harmoniosa em benefício do educando" (BRASIL, 1964, p. 16). Mas não escapa ao Conselheiro a clara noção que educação é criação de hábitos, nesse caso, "de natureza ética", que extrapola e muito os limites das rubricas disciplinares ou curriculares.

Educação integral, formação da consciência, criação de hábitos, ética, vida em comunidade, liberdade, participação são termos que compõem o léxico da ditadura - e não apenas dela - quando se trata de reivindicar uma pauta de 
educação política. Isso se evidencia no novo parecer exarado pelo CFE em 05/06/1964, o de número 136. Naquele documento, nova resposta ao Ministro da Educação, o qual pedia sugestões concretas ao Conselho para a objetivação da Educação Moral e Cívica - EMC nas escolas brasileiras, eram definidas algumas considerações preliminares. Entre elas, aquela que definia que toda a dinâmica escolar, com as suas possibilidades e os seus recursos, seria responsável pela EMC; que ela seria um objetivo das escolas de todos os graus; que para ela concorreriam os auxílios poderosos do rádio, da TV e do cinema, além da família e de todas as formas possíveis de comunicação (leia-se, propaganda).

$\mathrm{O}$ documento seguia denunciando os aspectos negativos ou contrários à EMC, o que demonstrava que esse era um campo aberto ao debate, à disputa, longe do consenso. Os aspectos arrolados, três no total, se referiam ao desconhecimento e à indiferença da população pela cultura e pelas instituições nacionais; ao excesso de autoridade escolar em detrimento da liberdade e do respeito à personalidade dos educandos e professores; e, por fim, o não cumprimento dos deveres por parte de todos os agentes escolares, da administração aos alunos. Ou seja, qualquer projeto de educação política precisaria começar por uma reforma da própria dinâmica escolar, na medida em que a escola, como uma pequena comunidade, deveria ser um exemplo a insuflar o espírito cívico da sociedade em geral.

Atendendo à solicitação do Ministro no que tange ao estabelecimento de recomendações para a implementação da EMC, o CFE definia como sendo a primeira e mais importante a "afastar esses e quaisquer outros fatores negativos" (BRASIL, 1964, p. 73). Novamente a política se confundia com respeito às instituições, à ordem, ao cumprimento de deveres e à valorização do que é nacional. Também aqui em nenhum momento emerge a discussão sobre direitos, sobre princípios democráticos ou sobre diferenças e pluralidade.

Subsiste a ideia de uma adesão e sujeição do indivíduo a uma mal definida comunidade - que pode ser a família, a escola ou a pátria - à qual ele deve se entregar de maneira resignada, mas consciente e ativa: "A educação cívica baseiase na integração social, e o objetivo da nova matéria é exatamente essa integração" (BRASIL, 1964, p. 73). O parecer deixava claro, ainda, os pontos de contato da disciplina OSPB com a antiga Instrução Moral e Cívica, denotando um claro processo de atualização de uma tradição. "Sensível aos estudos sociais e políticos, o estudante encontrará ao longo dessa disciplina, o esclarecimento sobre os problemas fundamentais sobre o seu tempo e o seu país, especialmente 0 conhecimento das instituições brasileiras" (BRASIL, 1964, p. 73).

A segunda das recomendações oferecidas ao ministério tratava da necessidade de o mesmo fomentar edições de "bons" compêndios de OSPB, de estudos brasileiros em geral e biografias de grandes vultos nacionais. Aqui, mais uma vez, a tradição se atualiza e é refirmado o primado nacionalista, estatal, e elitista daquela forma de educação política. Não é demais observar quais são os nove pontos propostos como aspectos positivos da sua implementação. Entre eles, o primeiro trata dos seus objetivos: 
Os objetivos primordiais que presidirão a qualquer iniciativa, serão: a boa prática de liberdade (sic!), o respeito aos ideais e opiniões pessoais; a noção de responsabilidade; o amor à tradição; o exercício da faculdade de ensino religioso; prática do trabalho, solidariedade social; o sentido de unidade nacional; o sentido de solidariedade internacional; as peculiaridades da nossa cultura". (BRASIL, 1964, p. 74, grifo no original)

Os outros oito pontos se referem à cooperação de todos os professores e de todas as disciplinas em uma obra comum; "a prática compatível do regime representativo dentre os alunos, como treinamento para a vida democrática"; a realização de excursões orientadas a outras instituições culturais (bibliotecas, monumentos, museus, etc.) e a instituições públicas tais como parlamento, tribunais etc.; o intercâmbio com instituições externas à escola, de caráter ético, cívico ou religioso, devidamente credenciadas; a promoção de comemorações e festas de caráter cívico e social; o zelo pela língua nacional; a organização de exposições e manifestações folclóricas; a utilização do ensino da música na prática de hinos, canções e composições regionais e das oportunidades esportivas (BRASIL, 1964, p. 74, grifos do original).

O parecer é finalizado com a sugestão de mobilização de todos os recursos de difusão de massa, públicos e privados, para a consignação daqueles propósitos, bem como de estabelecimento de encontros estaduais de professores realizados sob os auspícios dos Centros Regionais de Pesquisas Educacionais - CRPE's. Indica, ainda, a definição de Estudos Especiais sobre a temática a serem desenvolvidos pelos conselheiros Clóvis Salgado, Newton Sucupira, Edgar Renault, Borges dos Santos, Candido Padin e Almeida Junior.

Esse amplo parecer pode bem ser caracterizado como um Programa. Até porque muito do que seria a prática de Educação Moral e Cívica e Organização Social e Política Brasileira nas escolas do país durante o período ditatorial estava ali estabelecido e caracterizado. Basta lembrar que o Decreto n. 58.023, de 21 de março de 1966, assumia as considerações daquele parecer para definir o que fomentaria a educação e a consciência cívica de cada comunidade:

Art. $2^{\circ}$ - A educação cívica visa a formar nos educandos e no povo em geral o sentimento de apreço à Pátria, de respeito às instituições, de fortalecimento da família, de obediência à Lei, de fidelidade no trabalho e de integração na comunidade, de tal forma que todos se tornem, em clima de liberdade e responsabilidade, de cooperação e solidariedade humanas, cidadãos sinceros, convictos e fiéis no cumprimento de seus deveres. (BRASIL, 1966, p. 1)

O caráter transversal daquela prática se evidenciava no documento:

Art. $3^{\circ}$ - A formação cívica processa-se obrigatoriamente na escola, como prática educativa, mediante atitude frequentes que the assegurem a continuidade $e$ contribuam para a consolidação dos hábitos e ideais que ela colima. Deve ser praticada em todos os graus de ensino e ser preocupação dos professores em geral e, especialmente, daqueles que, em virtude de suas áreas de ensino, tenham com ela conexão, como linguagem, geografia, história, música, educação física e desportos, artes plásticas, artes industriais, teatro escolar, recreação.

Ao longo da década seguinte, a Educação Moral e Cívica e a Organização Social e Política Brasileira seriam disciplinas de estatuto próprio nas escolas brasileiras, com 
conteúdos, livros didáticos e práticas autônomas em relação a outras disciplinas, ainda que com elas articuladas. Os preceitos de uma "democracia indireta", de um sistema político praticamente sem oposição, de um ideal de família representado nas páginas de muitos livros didáticos por um sorridente casal branco, com um ou dois filhos, brancos, juntos a uma casa com um carro na garagem, atestavam o modelo de política ou de participação cívica que se esperava da população brasileira. Era o Brasil do "Ame-o ou deixe-o!", claro aviso para todos os insatisfeitos com aquela forma de educação política.

Apenas na primeira metade da década de 1980, no contexto da abertura democrática, e com a forte mobilização dos movimentos sociais, um conjunto de iniciativas de reforma da educação começou a colocar em xeque os preceitos herdados da ditadura. Novos conteúdos são discutidos para velhas disciplinas, mas algumas seriam abandonadas ao longo do decênio seguinte, tal o ranço herdado do período autoritário. Na senda reformadora, as disciplinas de EMC e OSPB, que seriam extintas em 1993, pela Lei 8.663, pareciam anacrônicas para os tempos de discussão da Assembleia Nacional Constituinte e para a escrita da nova Constituição Brasileira, de 1988. Ainda assim, pelo menos um exemplo é notável, no sentido de se valer daquilo que era o programa oficial para tentar dar um outro viés à educação política na escola brasileira. Trata-se do livro didático OSPB: Introdução à política brasileira, escrito por Frei Beto em 1985, frade dominicano perseguido, preso e torturado pela ditadura. Nele, e a partir de um contexto de produção absolutamente adverso, o autor tenta apreender um momento de forte transição em todas as dimensões da sociedade brasileira, conferindo à política uma dimensão de luta permanente pela construção de uma sociedade mais igualitária, menos perversa e autoritária, destoando completamente dos preceitos da disciplina até então (VIEIRA, 2011).

Já a EMC viu esvair-se gradativamente do seu peso nos currículos. Os seus conteúdos, fortemente marcados por uma longa tradição de preocupações com a moral, a higiene, o civismo, desapareceram ou foram diluídos nos temas transversais que marcariam a nova lei de Diretrizes e Bases da Educação Nacional aprovada em 1996 e, na sequência, os Parâmetros Curriculares Nacionais, a partir de 1997. Ainda que conclamada como uma Constituição cidadã, e a despeito dos significativos avanços da sociedade e da cultura brasileiras a partir de 1988, o tema da educação política parece ter desaparecido das preocupações gerais do país. Embora Abreu (2008) afirme o contrário, entendemos que a partir daquele momento a educação política deixou de fazer parte da agenda educacional brasileira, confundindo-se com um mal definido conjunto de preceitos sobre a cidadania, sendo este conceito ainda mais mal definido no país, não raro confundido com trabalho, mercado e consumo.

\section{A formação do italiano e o ensino da educação cívica na escola. Uma difícil história}

Embora a formação do cidadão tenha sido desde sempre uma das preocupações fundamentais subjacentes à escolarização, nem sempre a educação cívica recebeu na Itália a necessária atenção por parte da classe política e da própria escola. Na pátria de Maquiavel, um dos pais da política moderna, a disciplina que deveria ter majoritariamente formado o italiano democrático e republicano não somente foi regulamentada tardiamente, como conserva ainda hoje um caráter pouco definido. É este sem dúvida o principal motivo pelo qual a educação cívica ainda assume uma posição periférica na escola italiana, tanto 
para os professores quanto para os alunos e suas famílias.

Todavia, as premissas para que a educação cívica fosse colocada no centro do projeto político e pedagógico da Itália republicana, nascida com o referendo popular de 1946, foram expressivas e bem fundamentadas: desde a unificação política do país, no ano de 1861, a monarquia Savoia havia dedicado uma notável atenção à criação do italiano. Um exemplo válido é a frase, comumente atribuída a Massimo d'Azeglio, que bem traduzia a preocupação das classes dirigentes que emergiram com o Risorgimento: "Fizemos a Itália, agora devemos fazer os italianos" (SOLDANI-TURI, 1993, I, 17). Para atingir este objetivo a classe política liberal do século XIX iniciou um percurso tortuoso que talvez esteja ainda hoje incompleto, mas que tanto ela quanto a monarquia Savoia perseguiram com uma certa tenacidade (ASCENZI-SANI, 2016). Em segundo lugar, no ano de 1945 a Itália saía de mais de duas décadas de ditadura fascista, a qual havia promovido um ideal de cidadão bem preciso e havia tentando inserí-lo tanto na prática escolar quanto extra escolar, com instrumentos variados e, em certos casos inovadores, ainda que questionáveis: do livro do Estado às paradas militares, do serviço militar às intervenções sobre a política familiar, da ginastica na escola à propaganda intensiva em cada momento da vida pública.

Em vez disso, não obstante os esforços despendidos pela Assembleia Constituinte para dar sólidas bases democráticas à Itália, saída devastada no aspecto físico e moral do conflito, e contrariando os discursos dos vários governos que se sucederam após o término da Segunda Guerra Mundial, a formação do cidadão na escola recebeu pouca atenção por mais de uma década.

A educação cívica foi introduzida nas escolas secundárias italianas no dia 13 de junho de 1958. Esta medida, promovida pelo então Ministro da Educação Aldo Moro (CANESTRI, 1983), ${ }^{3}$ foi instituída ao fim de um acirrado debate sobre o tema Educação para a cidadania democrática, promovido pelos próprios professores (SANI, 1990), que tinham como constatar cotidianamente a falta de uma consciência democrática das novas gerações.

A proposta de Moro foi apoiada por boa parte dos partidos que ocupavam 0 parlamento à época, de liberais a comunistas, alguns dos quais até pouco anos antes se declaravam contrários à transmissão de um modelo de cidadão distante dos seus ideais políticos (SANI, 2004, p. 60). Os programas de 1958 atribuíam à educação cívica uma função tanto transversal em todas as disciplinas, promovendo nos alunos "razões de consciência moral e social" (ITALIA, Decreto del Presidente della Repubblica 585 de 13/06/1958), quanto disciplinar, para que fosse atribuído ao novo ensino um espaço específico no horário escolar. O ensino da educação cívica se manteve associado ao estudo da História, em virtude da estreita relação existente entre as duas disciplinas.

Todavia, a legislação também continha alguns problemas muito evidentes, que na verdade limitaram a sua aplicação: primeiramente, eram dedicadas ao ensino da educação cívica somente duas horas mensais, demonstrando o seu caráter subalterno em relação à História. Além disso, o programa oferecia uma apresentação resumida dos princípios constitucionais e dos ordenamentos do estado republicano, sem nenhuma menção à necessidade de promover nos cidadãos uma cultura democrática por meio da educação.

\footnotetext{
${ }^{3}$ Aldo Moro (1916-1978), representante do partido da Democracia Cristã, dirigiu o Ministério da Educação de 19 de maio de 1957 a 19 de junho de 1958 e de 1 de julho de 1958 a 26 de janeiro de 1959.
} 
Não por acaso, no texto da lei não apareciam termos como "democracia", "cidadania democrática" e "educação para a democracia". A nova disciplina, por conseguinte, parecia visar uma simples informação dos jovens, antes que uma formação da consciência democrática nas gerações mais novas (SANI, 2004, p. 61).

Por estes motivos, os novos programas foram recebidos com uma total desilusão, tanto pelos leigos quanto pelos católicos. Embora Aldo Moro defendesse no parlamento suas ações argumentando que o ensino, até então "inadequado, será certamente igualmente fecundo", na realidade muitas foram as resistências para introduzi-lo nas escolas. Também em função dos mesmos professores que atestavam a "falta" de consciência política dos alunos, pois em grande parte não estavam convencidos da utilidade da nova disciplina e, sobretudo, não haviam recebido nenhuma formação para ensiná-la (ITALIA, Atti Parlamentari, Senato della Repubblica, III Legislatura, Assemblea, 1749-1750).

\section{A educação cívica e a escola para todos}

Foi necessário esperar o ano de 1979 para que novos programas de educação cívica fossem estabelecidos no âmbito do decreto ministerial que definiria os conteúdos, as metodologias e o número de horas destinados às diversas disciplinas inseridas no plano de estudos das escolas médias (escola secundária de primeiro grau), criada no ano de 1962 para completar a escolaridade obrigatória estabelecida pelo artigo 34 da Constituição Italiana (1947). ${ }^{4}$

O objetivo das reformas daqueles anos era o de modificar a estrutura "verticalizada" e "hierárquica" da escola na intenção de promover no seu interior, com base também na influência exercida pelos movimentos de protestos de 68, uma participação dos vários sujeitos envolvidos no seu cotidiano, professores, pais e alunos, com a finalidade de conferir à escola "o caráter de uma comunidade que interage com a comunidade social e cívica mais ampla" (ITALIA, Decreto del Presidente della Repubblica 416 del 31/05/1974).

Os programas de 1979 referentes à escola média reservaram maior espaço para a educação cívica, na qual o ensino era fixado em uma base semanal, por um mínimo mensal de 4 horas. Interessante também foi a definição da educação cívica como "campo de preservação cultural e interdisciplinar", que implicou no compromisso responsável por parte de todos os docentes e a promoção de uma "convergência educativa" entre todas as disciplinas e cada aspecto da vida escolar. O objetivo central do ensino era o de promover nos alunos a assimilação de "comportamentos civilmente e socialmente responsáveis" por meio de uma progressiva tomada de consciência da complexa relação entre a liberdade do indivíduo e as necessidades da comunidade, entendida nos seus diferentes "níveis de agregação" (ITALIA, Decreto ministeriale del 9/02/1979, Programmi, orari di insegnamento e prove d'esame per la scuola media statale, p. 312). Pela primeira vez surgiu, também, a

\footnotetext{
${ }^{4}$ Os anos 70 assistiram a modernização da sociedade e da escola italiana. Naqueles anos foram aprovadas as leis sobre o divórcio (1970), sobre o aborto (1978), sobre a criação do Serviço Nacional de Saúde (1980) e, no que diz respeito ao sistema de ensino, se deu o fechamento das escolas especiais e das classes diferenciadas (1974), além da renovação dos programas e dos currículos de todos as modalidades de escolas. No Brasil alguns desses temas viriam à luz na década seguinte, de forte presença dos movimentos sociais na definição da Assembleia Nacional Constituinte e da Constituição de 1988. Assim como aconteceu nos governos de Silvio Berlusconi para o caso italiano, hoje o que se vê no Brasil é uma tentativa de reverter direitos arduamente conquistados pela população brasileira.
} 
referência à dimensão europeia e mundial: era uma perspectiva mais ampla que pressupunha uma ideia de educação que visava o desenvolvimento de uma mentalidade aberta, capaz de superar uma visão unilateral dos problemas comuns e, ao nível de compreensão, intuitivamente, definiria a existência de valores comuns aos homens apesar da diversidade das civilizações, das culturas e das estruturas políticas.

Outra novidade foi representada pela proposta de um ensino em caráter experimental diante de um modelo caracterizado, até então, pela simples transmissão de conteúdos, na tentativa de experimentar "um exercício concreto de vida democrática" nas salas de aula por meio do uso de formas de participação responsável. Os programas conciliavam, na verdade, o lançamento de experiências de cooperação por meio do trabalho em grupo, o qual, favorecendo a discussão fundamentada no diálogo, na tolerância e no respeito mútuo, evitariam "distorcidas e exacerbadas formas de competitividade" (ibid., p. 316). O professor era convidado a propor temas e atividades "adequadas às capacidades dos alunos", úteis para desenvolver "processos democráticos de decisão" e para fomentar atitudes de abertura ao diálogo, em acentuado contraste com o modelo de "transmissão ideológica" (ibid., p. 301).

As informações sobre as formas de organização civil e política da sociedade não eram mais propostas de modo fictício, mas apresentadas como o resultado de um processo histórico e "como pressuposto para posteriores desenvolvimentos", em sentido democrático, das instituições vigentes. O texto da Constituição Italiana era o núcleo fundamental da disciplina: nos dois primeiros anos, a ênfase era posta nos valores humanos e sociais nela presentes, os quais valorizariam a experiência comunitária do aluno (família, grupo, comunidade escolar); no terceiro a atenção centrava-se no estudo aprofundado do documento (gênesis, princípios inspiradores, modalidades de atuação) em uma lógica de comparação com as constituições de outros países, sobretudo europeus (ibid., p. 325-327).

O ensino da educação cívica foi estendido para a escola primária com os programas de 1985 que se colocaram em linha de continuidade com os de 1979. O modelo de homem e de cidadão ao qual faziam referência foram buscados não somente na Constituição da República, mas também nas declarações internacionais dos direitos humanos e da criança, tendo em vista a construção de uma escola que formava seus alunos para a "compreensão e cooperação com outros povos", com uma inovadora atenção para os modelos de referência não somente italianos.

Uma das finalidades do ensino da educação cívica na escola primária era a de fazer as crianças experimentarem os princípios de igualdade e dignidade na relação entre todos os cidadãos, além de promover a adoção de comportamentos baseados na "solidariedade ativa" e não na "passiva indiferença". Entretanto, no plano político o horizonte de referência era individualizado na União Européia (ITALIA, Decreto del Presidente della Repubblica 104 del 12/02/1985).

$\mathrm{Na}$ realidade, porém, nem os importantes programas como aquele de 1979 para a escola média e aquele de 1985 para a escola primária conseguiram revitalizar a educação cívica na escola italiana. Nem mesmo faltaram materiais didáticos e manuais especiais, cuidadosamente produzidos por editores e sistematicamente adotados de forma obrigatória nas escolas. Ainda assim, a educação cívica conservou um papel secundário nas mentes de professores e alunos. As razões eram, sem dúvida, muitas: de um lado, os professores não haviam recebido uma formação adequada sobre o tema e eram, por conseguinte, 
chamados a improvisar; do outro, a nova disciplina não podia competir com as disciplinas que tinham um maior peso na realidade e no percurso escolar dos alunos, como o Italiano, a Matemática e a História. Uma razão indireta, mas do nosso ponto de vista determinante, da pouca credibilidade da educação cívica, estava na evidente discrepância entre a supremacia dos princípios ensinados na escola e o baixíssimo nível de "vida" e participação política na realidade do dia a dia. A diferença entre os preceitos ensinados na escola e a sua prática cotidiana era evidente em todos os sujeitos do processo de formação, incluindo os estudantes, naturalmente.

Nos anos 90, diante da insatisfação geral observada nos debates sobre o ensino da educação cívica na escola, e também pela reação ao recente fim da assim chamada "Prima Republica" (1994), que entrou em decadência após os golpes da corrupção e os maus exemplos das péssimas relações entre a política e o mundo dos negócios, aquele ensino foi questionado. Buscou-se esclarecer o conteúdo de uma disciplina que era considerada inútil, por ser demasiadamente generalista. A primeira tentativa neste sentido foi registrada com a Portaria n. 58 de 1996. A parte intitulada Nuove dimensioni formative, educazione civica e cultura costituzionale propôs pela primeira vez concentrar as várias "dimensões educativas" do cidadão (afetiva, cívica, ambiental, entre outras) no estudo da Constituição. Se tratava, todavia, de uma tentativa exageradamente ampla de especificar os conteúdos de formação para a cidadania, ou mesmo de buscá-los na Carta Constitucional. Não por acaso, "o currículo contínuo de educação cívica e cultura constitucional" anunciado pela portaria, nunca entrou em vigor (CORRADINI-FORNASAPOLI, 2003, p. 77-78).

Poucos anos mais tarde, em 2000 , a lei 30 , relativa à reorganização dos ciclos escolares, assinada pelo ministro Luigi Berlinguer, e também não implementada completamente, introduziu pela primeira vez o ensino da "educação para a convivência civil" no lugar da educação cívica. A mudança da nomenclatura da disciplina e a passagem de "educação cívica" para "convivência civil" não tem, na nossa opinião, apenas um valor semântico, mas constitui o indício do desejo do Ministério de Educação de tentar reduzir mais concretamente os conteúdos da disciplina. Era a "convivência civil", na verdade, um conceito mais fácil de definir e, em alguns aspectos, de transmitir, em relação à educação cívica. Não é engano dizer que ela se constitui em uma parte, talvez aquela mais facilmente exequível, da necessidade de oferecer à sociedade os fundamentos éticos e comportamentais sociais considerados fundamentais, de modo a permitir a vida em comum. Mas educação cívica não é sinônimo de convivência civil, se não renunciando aos seus conteúdos elevados e abstratos, como a democracia e a referência a significados não escritos, mas fundamentais na vida de um Estado, como a ideia de pátria, de justiça social e de identidade coletiva.

Todavia, da lei 30/2000 em diante, a "educação cívica" como disciplina desaparece gradualmente da escola italiana para não mais retornar, enquanto a disciplina inerente à formação do cidadão torna-se objeto de atenção, até aquele momento não considerada, pelo Ministério da Educação. Na verdade, todos os ministros da educação se esforçaram para normatizar tal disciplina, tentando atualizar o conceito de educação cívica, hoje considerado como ultrapassado, tornando-o capaz de ser ensinado nas escolas.

A lei 53-2003, conhecida como "Legge Moratti", a partir do nome da ministra do segundo e terceiro governo Berlusconi, Letizia Moratti, começa a partir de onde parou 
Berlinguer. Como especificado nas Indicazioni nazionali relative al primo ciclo (decreto legge 59 del 19/02/2004), a educação cívica foi substituída pela "educação para a convivência civil". Aquela se justificava, por sua vez, nas seis "educações" definidas para serem ensinadas, seja de forma autônoma seja de forma transversal a todas as outras disciplinas. Tratava-se da educação para a cidadania, o meio ambiente, a segurança rodoviária, a saúde, a alimentação e a afetividade.

Na tentativa de tornar a educação cívica mais concreta, a Legge Moratti acabou por agregar aqueles conteúdos tidos como diferentes entre si. Aparentemente eles foram diminuídos, a partir de um ponto de apoio comum, uma vez que iam desde a "predisposição de menus equilibrados" para as cantinas escolares, até "arte pré-adolescente", às "problemáticas relacionadas com o tabagismo ativo e passivo", às "técnicas de controle de emoção, de relaxamento, de observação crítica da relação mente/corpo". Acima de tudo, desapareceram as referências aos mais altos valores universais, como a paz e a não violência, inseridos não por acaso na Carta Constitucional no dia seguinte à queda do fascismo, mas substituídos nas Indicazioni nazionali por alguns dos princípios fundamentais da economia neoliberal como, por exemplo, a atenção à saúde como elemento de responsabilidade do cidadão, muito mais que do Estado. Estabeleceu, ainda, a introdução formal da educação sexual, apresentada como elemento de inovação para a escola italiana, mas que se prestava, na realidade, a leituras fortemente ideológicas e, paradoxalmente contrárias à liberdade de consciência e do pensamento prescrito pela Constituição. Não por acaso, a lei não tratava de educação sexual, mas de educação para a afetividade, enquanto o Ministério da Educação produzia uma série de documentos nos quais o tema era tratado à luz de uma leitura religiosa, mais que afetiva ou higiênico-sanitária, contrariando, assim, a sensibilidade de uma parte importante da opinião pública.

Embora o sucessor da ministra Moratti, o secretário da educação Giuseppe Fioroni, tivesse feito a revisão da Lei 53-2003 um dos seus objetivos do programa, na realidade, conseguiu somente retardar o processo da sua implantação, sem modificar de fato o sistema, levado então até à supressão, pela ministra Gelmini, como veremos. Dada esta premissa, não causa surpresa saber que, também sobre o mérito da formação do cidadão o Ministro Fioroni não avançou muito mais em relação à sua antecessora, embora pertencesse a um partido político de inspiração oposta.

Renunciando definitivamente ao termo e ao conceito de "educação cívica", as Indicazioni nazionali per il curricolo per la scuola dell'infanzia e del primo ciclo d'istruzione (aprovadas em Julho de 2007) promoveram a "educação para a cidadania [...] através de experiências significativas, que consistem em aprender concretamente a tomar cuidado de si mesmo, dos outros e do meio ambiente e que forneçam formas de cooperação e de solidariedade". Tais "valores partilhados" e "atitudes de cooperação e colaboração" constituíam "a condição para a prática da convivência civil" e para iniciar aquilo que significativamente definia um "novo humanismo" (ITALIA, Ministero dell'lstruzione, Università e Ricerca, Indicazioni nazionali per il curricolo per la scuola dellinfanzia e del primo ciclo d'istruzione, 2007). A única diferença significativa em comparação com a lei Moratti foi a eliminação do currículo dos seis tipos de educação das quais foi destacada a educação para a convivência civil, remetendo, ao contrário, a não especificados "princípios fundamentais" da disciplina, que deveriam integrar transversalmente todas as outras.

A intervenção regulamentar mais profunda e substancial no ensinamento da 
educação cívica foi implementada pela ministra Mariastella Gelmini, ao longo dos anos do último governo de Berlusconi (maio de 2008 a novembro de 2011). Com a lei 133-2008 a disciplina foi denominada "Cittadinanza e Costituzione", a qual substitui definitivamente tanto a educação cívica quanto a educação para a convivência civil.

$\mathrm{Na}$ apresentação do novo ensino, que trazia a assinatura da mesma ministra, notase que o objetivo da lei era ensinar duas das competências descritas nas Raccomandazioni del Parlamento europeo relative alle competenze chiave per l'apprendimento permanente: as competências sociais e as competências cívicas. Para este fim, era necessário abandonar de uma vez por todas a forma tradicional de se ensinar a educação cívica, a qual "embora referindo-se as normas e princípios comuns e instituídos ao mais alto nível [...] era, por sua natureza, suscetível de rebaixamento a improdutivos debates, divergências, conflitos ou, ao oposto, a discursos abstratos e pouco interesses aos jovens" (ITALIA, Ministero dell'Istruzione, Università e Ricerca, Documento d'indirizzo per la sperimentazione dell'insegnamento di Cittadinanza e Costituzione, 2007). Tratava-se, pelo contrário, de dar uma base concreta e facilmente compreensível a uma disciplina fundamental na vida do Estado. Operação, esta, longe de ser fácil de realizar, especialmente com uma disciplina comumente reconhecida como não importante no decurso dos estudos.

A fim de alterar a situação, pela primeira vez na história da escola italiana, a reforma definia para a nova disciplina uma hora de aula semanal e uma avaliação distinta daquela da disciplina de História, embora a ministra se declarasse bem consciente do fato que "uma hora semanal dedicada a Cidadania e Constituição certamente não é suficiente para produzir resultados concretos."

Em um esforço para obter maior operacionalidade e eficácia, a lei 133-2008 convidava, por conseguinte, os professores para que em conselhos de classe fossem "buscados acordos para conseguir avaliar conjuntamente o comportamento das crianças, dos adolescentes e dos jovens. Enriquece-se de tal modo o conceito tradicional de conduta". Na realidade, porém, combinar a avaliação de Cidadania e Constituição com a avaliação de condutas, como proposto pela Lei Gelmini, não só é de difícil implementação, como também sempre haverá o risco da sua observação ser contrária ao entendimento do conteúdo e dos princípios que a disciplina deveria transmitir. Isto, com efeito, se por um lado se inspira o respeito das regras sociais e aos outros; por outro, se aqueles conteúdos e princípios se tornam apenas partes reproduzíveis do contexto interno da escola que funciona, por vezes e pela sua natureza, como um microcosmo com uma forte hierarquia, a qual influencia fortemente relações interpessoais entre alunos e professores e entre professores e autoridades escolares. Além disso, porque o respeito pela Constituição e pela disciplina escolar não são conceitos e muito menos práticas equivalentes, caso o conselho da ministra fosse de fato aplicado, aos professores seria atribuída a tarefa - do nosso ponto de vista pouco sensata - de tratar e julgar os jovens não só como estudantes, mas também como cidadãos. Isso, sem que eles, professores, possuíssem elementos suficientes para exercer um poder tão forte e invasivo da vida privada dos alunos.

Ainda, o apelo da lei Gelmini à Constituição, presente desde o título da nova disciplina, explica-se com o desejo da ministra em instituir a educação do cidadão sobre aquele que a opinião pública italiana comumente considera a base - sólida e confiável - da vida democrática e republicana. Todavia, a lei atualmente em vigor prova que não basta 
estudar a Constituição, por mais importante que seja, para formar bons cidadãos. Essa compreende, na verdade, dois limites muito evidentes: o primeiro, de modo geral, é que formar o indivíduo capaz de respeitar as leis de seu país não significa formar automaticamente um homem consciente dos seus direitos e dos seus deveres com todos os seus semelhantes. Em determinados contextos leva, de fato, a reforçar as barreiras nacionalistas, regionalismos, a diferenciar os nacionais dos estrangeiros, os europeus dos não europeus, "nós" de todos os "outros". Paradoxalmente, a Constituição poderia tornarse uma maneira de fazer surgir novas formas de identidade nacional, de intolerância e de rejeição a diversidade e não o "novo humanismo" preconizado pela recente intervenção normativa. Algo semelhante se avizinha se for aprovado o projeto que define uma "Escola sem Partido", no Brasil.

O segundo limite, particular da situação italiana, é que a abordagem de educação cívica como aquela atribuída pela lei Gelmini termina por repetir um ensino eminentemente moral e abstrato da temática afeita à política, destinado a enfraquecê-la e a torná-la ainda mais inútil, quando não alcança os interesses dos estudantes. Especialmente em contexto históricos tais como o italiano ou o brasileiro, nos quais quem deveria se mostrar exemplar na aplicação da Constituição frequentemente a desqualifica ou ignora. Aliás, o uso da Constituição relacionada a avaliação de "condutas "seria inadequado, para além da difícil implementação, também para aqueles que a escreveram ou deveriam zelar pelo seu cumprimento.

\section{Considerações finais}

Considerando que a situação cultural e política atual não fornece para as forças políticas progressistas elementos suficientes para construir um modelo de homem e cidadão, que atenda os novos desafios globais (e mesmo os locais!), e consequentemente não propõe um projeto formativo para realizá-lo, não é de se estranhar que as propostas de reforma provenham exclusivamente pelas forças conservadoras, seja na Itália ou no Brasil. É, com efeito, muito mais simples apresentar uma atualização do velho modelo de cidadão antes que elaborar um novo. Pena que o exemplo a que se referem os conservadores é ainda um cidadão obediente, não crítico, amante da pátria e do governo, confiante em seu trabalho e, portanto, submisso. Se olharmos no seu conjunto, na verdade, as reformas brasileiras e italianas dos últimos 70 anos são animadas pelo mesmo espírito: formar cidadãos não acostumados a serem críticos, obedientes, pouco conscientes. Fosse pretendendo ensinar a política de forma transversal, ou através de rubricas curriculares próprias, normalmente as suas finalidades eram mascaradas. Mais ou menos conscientemente, as propostas de educação política nas escolas disseminavam discursos em torno da necessidade de eficiência, na busca de fornecer competências consideradas "realmente" úteis para os países, evitando discussões e conflitos, polêmicas e divergência de ideias, em vez de garantir o bom funcionamento da escola pública para todos. Porém a educação, para cumprir seu papel, precisa também do dissenso, do confronto, talvez de um intenso desacordo. Ela necessariamente se dá também através do exemplo da parte de quem educa e de como se gerencia tais dissensos.

De fato, a principal razão do fracasso do ensino da educação cívica não está nos programas, os quais podem ser modificados continuamente, mas na falta de um modelo factível de homem e de cidadão a ser transmitido para as gerações mais jovens. A crise da 
educação política, na verdade, não é didática, mas de conteúdo, ou melhor, tem relação com o ideal de cidadania que se almeja, e que hoje não é, na realidade, muito claro ou compartilhado como podia ser a décadas atrás, sob regimes ou períodos menos democráticos. É nossa própria civilização, baseada nos direitos, que vem sendo hoje constantemente questionada, de tal maneira que não sabemos nem mesmo encontrar um lugar para os deveres, como sugere Hannah Arendt (1998; 2014). E por essa razão estão naturalmente em dificuldade a educação e a instrução. A escola está por um momento ainda em pé, assim como a democracia, embora nenhuma das duas goze de boa saúde. É inegável, todavia, que sobretudo o sistema educativo no mundo ocidental tem sido chamado ao banco dos réus para se defender da acusação de não trabalhar o suficiente para construir um mundo melhor ou, ao menos, para defender aquilo que as gerações passadas nos legaram.

A tarefa de hoje é, com efeito, mais árdua, por uma série de razões, das quais tentaremos ilustrar as mais importantes. Inicialmente, se pode identificar uma causa que tem suas raízes no passado e que remonta as tragédias provocadas pelos regimes totalitários durante o século XX. Fascismo, nazismo e comunismo, em todas as suas versões, na Europa, na América Latina, assim como no resto do mundo, tinham um modelo de cidadão bem claro, contudo, absolutamente não aceitável, e possuíam instrumentos de transmissão muito eficazes. Os totalitarismos novecentistas têm demonstrado aos historiadores e aos educadores, como a escola e a formação não são boas por si, mas em relação à mensagem que se quer transmitir. Ao contrário do que poderiam imaginar os pensadores iluministas, que tiveram grande mérito na construção da civilização dos direitos que herdamos da modernidade, um homem do século XXI sabe que não basta frequentar a escola para criar cidadãos e homens melhores.

Outras causas podem ser encontradas no presente nas transformações produzidas sobre o modo de entender a escola e a educação na chamada pós-modernidade. Em particular, a dificuldade de definir hoje um ensino de educação cívica ou política realmente útil e convincente para os professores, alunos e famílias nos parece derivar de dois aspectos típicos da cultura "líquida" na qual vivemos (BAUMAN, 1999): o predomínio da economia sobre todos os outros aspectos da vida social e a passagem do sujeito ao perfil.

O primeiro tema é fruto de um percurso iniciado com a Revolução Industrial. A partir da consolidação do capitalismo as elites produtivas solicitaram aos governos o fortalecimento das políticas de escolarização das massas para satisfazer a crescente necessidade de ingresso nas fábricas, de tecnologias e de processos de produção cada vez mais complexos. Começou-se, assim, a falar em educação como "bem" e da população instruída como "capital humano", como viria propor mais tarde Theodore Schultz (1967). Ainda hoje, quanto mais uma população é instruída, maior é o seu valor econômico. Em consonância com as demandas da economia aos poucos a escola tem renunciado ao mandato institucional de formar o cidadão para concentrar-se primeiro sobre o trabalhador e depois sobre o consumidor. Aqui a política pouco importa.

De acordo com essa abordagem e em nome de um exigido esforço para a sua concretização, entre os Oitocentos e os Novecentos, a escola na verdade estabeleceu como objetivo principal a formação moral e instrumental do trabalhador, esforçando-se em oferecer aos estudantes o ethos necessário para que fossem inseridos com sucesso no mercado de trabalho, tanto quanto para manterem a sua posição/condição social. Nas 
últimas décadas, em contrapartida, em decorrência da afirmação da mentalidade consumista e da crise da economia, a educação tendeu perigosamente em direção a formação do consumidor, mais ainda do que do trabalhador.

As mesmas linguagens da educação e do ensino parecem atestar a adoção no âmbito escolar da lógica e dos parâmetros da economia neoliberal. Além disso, tal transformação ocorreu quase inconscientemente. Os exemplos poderiam ser inúmeros, mas nos limitaremos àqueles mais evidentes: a trajetória de estudos em todos os aspectos da escola, por exemplo, não é mais baseada nos currículos, mas nas "competências", termo igualmente proveniente da economia. E o que dizer do "porta-fólio", que para os estudantes universitários tem concorrido com o tradicional caderno? Ou do fato de os estudantes do ensino superior, no caso italiano, não realizarem mais os "exames de recuperação", mas acumularem "débitos formativos"? Débitos que, da mesma forma como no andamento da economia atual são bem mais frequentas que os créditos (DEL REY, 2010). Sem contar que as investigações e avaliações mais aprofundadas sobre o sistema escolar nacional e internacional são desenvolvidas não por entidades que se ocupam da infância e da educação, como é o caso da Unesco, mas por organizações econômicas, a primeira entre todas a OCDE, Organização para a Cooperação e Desenvolvimento Econômico. Não obstante essas limitações no entendimento do que seja educar e, por conseguinte, no sentido último da escola, o capitalismo tem conseguido produzir uma sensibilidade que se retroalimenta da redução da vida e do mundo ao homo economicus.

O segundo tema refere-se à ideia de "indivíduo" típico da pós-modernidade: o perfil. O "sujeito" é hoje concebido como um conjunto de partes a serem "formadas" separadamente, no âmbito didático das chamadas "competências", que podem ser inseridas ou eliminadas tendo como base as necessidades de cada momento. Este é o cerne da reforma curricular estabelecida por decreto em 2016, no Brasil, para o ensino secundário e da atual proposta de Base Nacional Comum Curricular. O indivíduo da pósmodernidade perdeu a sua profundidade para se tornar uma base sobre a qual podem ser aplicados ou dela eliminados modelos convenientes aos interesses econômicos prevalentes. Alguns "papéis" a serem cumpridos têm uma natureza orgânica e material, tais como a doação de órgãos, o controle da sexualidade, a cultura fitness ou os dispositivos sanitários de "vida ativa", outros são fornecidos pela cultura, ou seja, na escola, como as competências. Como explica Miguel Benasayag, hoje a unidade que agrega as várias partes do homem provém não tanto da sua condição de ser social, sujeito de expectativas e necessidades, mas do meio externo, da sua conformidade com o perfil pré-definido, última fronteira do "reducionismo" pós-moderno (BENASAYAG, 2016). Na época do perfil se corre seriamente o risco de pensar uma sociedade em série, feita de indivíduos construídos à imagem e semelhança de um modelo que, na realidade, não está bem definido no seu aspecto final, mas que pode ser modificado a bel-prazer conforme as exigências do momento, que normalmente respondem aos imperativos econômicos.

Com a passagem para a definição de perfis em série, como sugere Aldous Huxley na sua utopia do Admirável Mundo Novo (1946), a ideia de perfil nos faz perder as subjetividades e as singularidades, pois tudo é premido pela lógica dos big-data - e os indivíduos deixam de ter importância pois, afinal, há um perfil "universal" desejado. Além disso, o indivíduo típico do pensamento hegeliano, associado a um destino comum com os seus semelhantes, na pós-modernidade é desterritorializado, isolado não só de seus pares 
e do seu território-lugar, mas também da realidade mesma, para ser analisado assim como uma abstração, como resultado de processos e de módulos reproduzíveis de maneira idêntica em cada parte do mundo, em nome do princípio supremo da flexibilidade (TÜRKHE, 2015).

À luz de tal ideia de homem parece mais compreensível a razão pela qual frequentemente, hoje, a educação entendida como formação torna-se mera retórica e é reduzida à aprendizagem de competências, pensadas como instrumentos mais adequados para enfrentar uma concorrência global. $E$ mais ainda, se compreende porque é quase impossível se transmitir um modelo de cidadão convincente. Afinal, por que e a quem interessaria a política e a sua educação?

Para restituir o vigor das preocupações com a educação cívica, seria preciso um novo momento constitutivo daquele ensino, que ultrapassasse as questões terminológicas e curriculares, para enfrentar, em contrapartida, o papel que a escola pode ter na formação do homem e do cidadão na chamada pós-modernidade. A didática e a pedagogia podem fazer a sua parte, mas é preciso, porém, um novo projeto cultural e educativo a ser transmitido pela escola. E precisamos sobretudo colocar os jovens na condição de experimentar de forma ativa os valores considerados positivos da nossa civilização, a igualdade, a democracia, os direitos, os deveres, a alteridade, o respeito e a tolerância, fundamentais para o desenvolvimento da vida realmente democrática. De fato, se a democracia é antes de tudo um estilo de vida, um habitus, como haviam definidos os antigos, ou ainda, nas palavras de Dewey, "um modo de vida associado ao conjunto de experiências comunicadas" (DEWEY, 1916, p. 101), a única forma de aprende-la é aquela que a coloca em prática, que a vive em primeira pessoa em relação com os outros, mais do que sobre ela ouvir dizer, na escola ou fora dela.

\section{Referências}

ABREU, Vanessa Kern. A Educação Moral e Cívica: disciplina escolar e doutrina disciplinar - Minas Gerais (1969-1993). 2008. Dissertação (Mestrado em Educação) Programa de Pós-Graduação em Educação, Universidade Federal de Uberlândia, 2008.

ARENDT, Hannah. A condição humana. Rio de Janeiro: Forenze, 2014.

Entre o passado e o futuro. São Paulo: Perspectiva, 1998.

ASCENZI, Anna-SANI, Roberto. Tra disciplinamento sociale ed educazione alla cittadinanza: L'insegnamento dei Diritti e Doveri nelle scuole dell'Italia unita (1861-1900). Macerata: EUM, 2016.

BAUMAN, Zigmunt. In Search of Politics. Redwood City: Stanford University Press, 1999. BENASAYAG, Miguel. I/ cervello aumentato l'uomo diminuito. Trento: Erikson, 2016.

BETTO, Frei. OSPB: introdução à política brasileira. São Paulo Ática, 1985.

BITENCOURT, Circe. Patria, civilização e trabalho. O ensino de História nas escolas paulistas (1917-1939). São Paulo: Loyola, 1990.

CANESTRI, Giorgio. Aldo Moro ministro della Pubblica Istruzione. In: AA.VV. Aldo Moro: cattolicesimo e democrazia nell'Italia republicana. Alessandria: Istituto di storia della Resistenza di Alessandria, 1983.

CORRADINI, Luciano; FORNASA, Walter; POLI, Sergio (Orgs.). Educazione alla convivenza civile: Educare Istruire Formare nella scuola italiana. Roma: Armando, 2003. 
p. 77-78.

DEL REY, Angélique. À l'école des compétences. De l'éducation à la fabrique de l'élève performant. Paris: La Découverte, 2010.

DEWEY, John. Democracy and Education. New York: The Macmillan Company, 1916. p. 101.

DIEHL, Astor. A. A cultura historiográfica brasileira: do IHGB aos anos 1930. Passo Fundo: EDIUPF, 1988.

HORTA, José Silvério Baia. O hino, o sermão, a ordem do dia. Campinas: Autores Associados, 2012.

HUXLEY, Aldous. Admirável mundo novo. Lisboa: Editores Associados, 1946.

LENHARO, Alcir. Sacralização da política. Campinas: Papirus, 1986.

ODALIA, Nilo. As formas do mesmo: ensaios sobre o pensamento historiográfico de Varnhagem e Oliveira Viana. São Paulo: UNESO, 1997.

SANI, Roberto. La scuola e l'educazione alla democrazia negli anni del secondo dopoguerra. In: CORSI, Michele; SANI, Roberto (Orgs.). L'educazione alla democrazia tra passato e presente. Milano: Vita \& Pensiero, 2004.

. Le associazioni degli insegnanti cattolici nel secondo dopoguerra 1944-1958. Brescia: La Scuola, 1990.

VIEIRA, Cleber Santos. Livros didáticos e cultura política: OSPB em tempos de Nova República. Cadernos de História da Educação, Uberlândia, v. 10, n. 1, jan./jun. 2011, p. 71-82.

SCHULTZ, Theodore. O valor econômico da educação. Rio de Janeiro: Zahar, 1967.

SOLDANI, Simonetta-TURI, Gabriele. Fare gli italiani: Scuola e cultura nell'Italia contemporânea. Bologna: II Mulino, 1993.

TÜRKHE, Christoph. Cultura do déficit de atenção. Serrote. São Paulo: Instituto Moreira Salles, 2015. p. 51-61.

MARCUS AURELIO TABORDA DE OLIVEIRA é professor na Universidade Federal de Minas Gerais, Doutor em História e Filosofia da Educação pela PUC/SP.

Endereço: Rua Padre Demerval Gomes, 244, ap. 203 - 30-535-470 - Belo Horizonte/MG Brasil

E-mail: marcustaborda@pq.cnpq.br

PAOLO BIANCHINI é professor na Universidade de Turim, Doutor em História pela Universidade de Turim.

Endereço: Via Gaudenzio Ferrari, 9/11 - 10124 - Turim - Italia

E-mail: paolo.bianchini@unito.it

Recebido em 30 de novembro de 2016.

Aceito em 20 de dezembro de 2016. 